\title{
DIÁLOGO DAS FONTES E RACIONALIDADE JURÍDICA: UM OLHAR À PROTEÇÃO HORIZONTAL DOS DIREITOS DAS MULHERES.
}

\section{DIALOGUE OF SOURCES AND LEGAL RATIONALITY: ONE LOOK AT HORIZONTAL PROTECTION OF WOMENS`S RIGHT}

\author{
${ }^{1}$ Marjorie Evelyn Maranhão Silva Matos
}

\section{RESUMO}

Através do presente trabalho pretende-se analisar em que medida a aplicação da Teoria do Diálogo das Fontes no Brasil pode contribuir para a proteção dos direitos das mulheres. Parte-se da construção racional de seus direitos que, fundados nos direitos humanos, justificam-se, (também) de forma horizontal, nos direitos prescritos para outros grupos vulnerabilizados. Então, a pluralidade de justificações de direitos de outras ordens, pelo método dedutivo, pode servir de justificação também dos direitos das mulheres, pois não há exclusão de umas fontes pelas outras. Pelo contrário, a unidade do sistema jurídico termina por exigir uma vinculação entre uns direitos e outros.

Palavras-chave: Diálogo das fontes. Racionalidade jurídica. Proteção horizontal. Gênero. Direitos da mulheres.

\section{ABSTRACT:}

The present work aims to analyze to what extent the application of the Theory of Dialogue Sources in Brazil can contribute to the protection of women's rights. A part-rational construction of their rights, based on human's right, justified, also horizontally, within the prescribed rights to other vulnerable groups right. Thus, the plurality of justification of other person's right, by the deductive mode, also serves of justification for the women's rights, as one source doesn't exclude another one. On the contrary, the unit of juridical system demands a link between all the rights.

Keywords: Dialogue of sources. Juridical rationality. Horizontal protection. Genre. Women`s rights.

\footnotetext{
${ }^{1}$ Mestranda em Direito pela Universidade Federal do Pará (UFPA)Belem,Pará. Pós-graduada em Direito Penal e Processo Penal pela Universidade Católica Dom Bosco (UCDB) Campo Grande, Mato Grosso do Sul, Brasil.
} 


\section{INTRODUÇÃO}

A mulher vive, até hoje, um tenso, intenso e doloroso processo de reconhecimento de direitos. A desproteção deles se tornou um problema de interesse mundial, pois atinge "todas as sociedades", indistintamente. Para que ela possa ser entendida, então, precisa ser vista como um processo histórico de dominação, de sexismo e de supremacia masculina, que se contrapõe às ideias de respeito aos direitos humanos.

O fato de haver uma construção apenas individual dos discursos assecuratórios dos direitos das mulheres faz com que eles (assim como os dos outros grupos vulnerabilizados) fiquem fragilizados, na medida em que se fraciona a própria construção racional de sua fundamentação.

Quando, por outro lado, não são vistos de modo individualizado, mas como partícipes do ordenamento jurídico como um todo, mais firme se torna a sua existência, assim como a dos direitos dos outros grupos, razão pela qual se exige uma visualização coletiva desses direitos.

Assim, busca-se, através do método dedutivo, analisar em que medida esse diálogo entre as fontes dos vários ramos do direito, a partir da construção do pensamento jurídico racional, pode contribuir para a salvaguarda horizontal dos direitos das mulheres.

Para se atingir esse fim, o trabalho foi estruturado de modo a tratar, primeiramente, de algumas noções sobre a Teoria do Diálogo das Fontes, passando-se, em seguida, à construção dos direitos humanos pela interseção entre ela e a racionalidade jurídica. Por fim, discorre-se sobre as contribuições do diálogo das fontes para a proteção horizontal dos direitos das mulheres.

\section{TEORIA DO DIÁLOGO DAS FONTES: ALGUMAS IMPLICAÇÕES JURÍDICAS}

A construção e o reconhecimento do direito são expressados a partir das suas fontes, que, pela própria expressão, já indicam a ideia de nascedouro, berço. Não é possível pensar em direito, então, senão a partir delas, que são a expressão de tudo aquilo que o direito enuncia, sendo o seu começo e seu fim, já que o direito gira em torno e se demonstra pelas suas fontes. 
As profundas transformações históricas acontecidas quando do reconhecimento dessas fazem transparecer a importância de seu estudo e a necessidade de constante adequação dessas à ("nova") visão do mundo jurídico. Assim, falar de fontes do direito é falar de constante redimensionamento de sua importância e das várias interfaces jurídicas que elas enunciam.

Não obstante a existência de outras fontes do direito, neste trabalho, entende-se como destacada das outras a doutrina, já que ela é fundamental à construção e correção do direito, por, especialmente, amoldar a situação social ao mundo jurídico, trazendo-lhe o valor e o reconhecimento que merecem. É por essas razões que o trabalho ressalta o valor da doutrina como fonte de construção e desconstrução jurídicas, enquanto justificativa para a existência dos direitos.

Por oportuno, registre-se que o reconhecimento da importância doutrinária sobre a legislação e as demais não é uníssono. Tal fato é destacado por Adeodato (2012), que ressalta que há, no mundo jurídico, um crescimento da importância das fontes estatais em detrimento das fontes espontâneas.

Todavia, filia-se este trabalho à corrente que reconhece o sobressalto doutrina sobre as demais, cuja importância é referenciada por Clóvis Beviláqua (2015), ao reconhecer que, antes do direito ser previsto nas leis, é pela doutrina que ele é tratado, e é ela que "entrega" ao legislador aquilo que será transposto para a legislação.

Não se quer, com isso, desconsiderar a relevância das outras fontes. Quer-se somente considerar a doutrina como essencial à conjugação daquilo que está disperso nas demais, a partir do reconhecimento, por parte dela, das parecenças entre os diversos ramos, o que vai gerar uma relação necessária para o reconhecimento de algo efetivamente como "de direito".

Também, mesmo que a doutrina, por si só, não seja capaz de alterar o sistema de leis, é a partir dela que ele sofre suas mutações, inclusive resolvendo-se eventuais "problemas" que possam ali surgir.

Isso porque, não raramente, surgem colisões entre as leis (e também entre costumes e decisões) (BOBBIO, 1999), que precisam ser resolvidos a partir da observação (também) do entendimento doutrinário sobre seu reconhecimento.

Ainda, há conflitos, muitas (senão “todas as") vezes, também dentro da própria doutrina. Esses são importantes para que possam ser pensadas as relevâncias que os institutos e as situações jurídicas têm, dentro de determinados contextos. Só assim, é possível perceber, de fato, qual é o entendimento jurídico mais relevante a ser adotado quando de certa situação. 
Então, a própria doutrina que os cria, também os resolve. É assim que ela se confirma como fundamental à promoção de direitos, já que serve para assegurar a (apenas) transitoriedade desses fenômenos de "precariedades jurídicas", que precisam ser resolvidos para que a solidez e a unidade do sistema jurídico sejam preservadas.

Tal transitoriedade se liga à ideia de Bobbio (1999) de unidade, já que ele reconhece o não isolamento das normas jurídicas, que precisam ser pensadas dentro de um contexto e um “todo", que é o ordenamento jurídico. Desse modo, a construção normativa precisa refletir-se enquanto pertencente a um conjunto, o que assegura a integralidade do ordenamento e a suficiência das fontes.

Para Joseph Paz (1991, p. 175), os sistemas jurídicos “[...] pretenden autoridad para regular cualquier tipo de conducta", demonstrando que eles devem ser suficientes e compreender todas as situações reguladas como jurídicas. E isso também os difere dos demais sistemas institucionalizados.

Ramón Soriano também discorre sobre essa necessidade do sistema abarcar todas as situações jurídicas, ressaltando que "La plenitud - también llamada completud - del ordenamiento jurídico es la cualidad que le hace contener soluciones para todos los conflictos jurídicos que puedan originarse en su seno" (1993, p. 141).

Nessa linha, as inconsistências da legislação, tanto na ordem de lacunas, como de antinomias, precisam ser corrigidas para que seja preservada sua unidade e congruência. Isto se faz a partir do preenchimento das arestas da legislação, bem como por meio da preservação de um dispositivo sobre o outro menos relevante (para aquele caso) (FERRAZ JUNIOR, 1995).

E a doutrina se mostra de grande valia para a correção dessas ocorrências, de forma que é a partir dela que são formulados os (novos) pensamentos sobre as situações jurídicas, trazendo adequação do direito à atualidade, e assegurando o resguardo de direitos igualmente fundamentais.

Sem ela, não seria possível entender o que une os tantos ramos jurídicos e resolver esses problemas de modo a preservar os interesses maiores do direito, ajustando a resolução da situação à realidade e preenchendo seu sentido de existência. Pelo contrário, esvaziar-se-ia o direito de sentido e fragmentá-lo-ia, e também se contraporia à ideia de isonomia entre os direitos essenciais que o compõem.

E é a igualdade fundamental entre os diferentes ramos do direito que embasa a "conversa" entre eles e suas fontes, que devem ter uma aplicação coordenada (BENJAMIN, 
2012, p. 5-7), uma vez que é pelo diálogo que se sustenta a necessidade de se articular os "diversos direitos" a partir de um mesmo fundamento, um núcleo essencial, que vai assegurar a suficiência de suas fontes.

Assim, é essa "conversa" (BENJAMIN, 2012, p. 5-7), é o diálogo entre as diversas fontes, que servirá para a salvaguarda de direitos enquanto baseados uns nos outros, e como efetivamente pertencentes ao mesmo conjunto jurídico.

A Teoria do Diálogo das Fontes entrou no mundo jurídico para romper com o paradigma de separação dos ramos do direito. A ideia era afastar a individualidade e inserir uma visão coletiva dos direitos, enquanto fundamentados uns nos outros, o que proporcionava uma proteção a partir de uma multiplicidade direcional, guiada por uma construção racional da existência deles.

A professora Cláudia Lima Marques foi responsável por trazer para o Brasil a Teoria alemã do Diálogo das Fontes, pensada, inicialmente, pelo professor Erik Jayme, em 1995. Sua ideia era desenvolver interseções entre os diversos ramos do direito, para que, pensando-os de forma coletiva, eles pudessem ser eficazmente justificados (CAMPOS, 2013).

A unidade do ordenamento jurídico fazia-lhe pensar na não exclusão de um ramo do direito com relação a outro. Pelo contrário, trazia-lhe a necessidade de visualização deles de forma integrada e complementar, de modo a assegurar a permanência e confirmação dos já existentes, assim como a construção de novos e necessários direitos (MARQUES, 2012).

Segundo Campos (2013), a professora Cláudia Lima Marques explicava a ideia de diálogo a partir da lógica do pensar, que ligava duas ou mais fontes do direito que, de modo coerente, convergiam em algum ponto, demonstrando a igualdade, em certos aspectos, entre elas. Desse modo, o ponto em comum dos diversos ramos fazia com que eles passassem a ser reconhecidos como tendo os mesmos fundamentos de existência e de manutenção.

Os ensinamentos dela seguiam no sentido de reconhecer a parecença entre os diversos ramos do direito (para ela, parecença especialmente existente entre o Direito Civil e o Direito do Consumidor), de modo que as normas jurídicas não serviriam para aplicação a apenas um campo do direito, mas ao direito como um todo, pela ligação entre seus ramos (MARQUES, 2012).

Assim, quando da existência de conflitos ou silêncio das normas, haveria a necessidade de resolução a partir das soluções advindas de outras normas, num processo de fundamentação e complementação de uns direitos por outros, para construir uma ideia de integralidade jurídica, fundada na completude de Bobbio (1999). 
Os direitos passavam, então, a não ficarem estagnados dentro de seu "próprio mundo", pois pensava-se no rompimento das barreiras limítrofes de cada um deles. Trazia-se a ideia de não-hierarquização, mas de multiplicidade de fatores promovendo a reunião deles. Isso permitia fazer a aplicação simultânea de duas ou mais fontes para um mesmo caso, ou a aplicação de uma de modo complementar à outra, para resolver as questões jurídicas (CAMPOS, 2013).

Assim, a nova realidade jurídica, criada pela possibilidade de aplicação de uma fonte não feita, inicialmente, para tratar de um certo caso, a ele, ampliava o leque de justificações jurídicas, que ultrapassavam os limites legislativos, para se estender a tantos casos quanto o mundo do direito permitisse.

Para Campos (2013), dessa maneira, assegura-se a possibilidade de extensão de uma fonte para a proteção de outros hipervulneráveis não protegidos por ela, a partir do diálogo entre essas fontes e as situações jurídicas. E as ideias de direitos humanos e de dignidade são as que sustentam esse diálogo, objetivando a proteção dos indivíduos e grupos vulnerabilizados.

Assim, a superação das limitações legislativas gerou a coordenação e a aplicação de fontes diferentes a um mesmo caso, fundadas na proteção dos direitos fundamentais da pessoa humana. Desse modo, a Teoria do Diálogo das Fontes trouxe uma mudança de paradigma para o direito, com a constituição de uma conjugação dos diversos ramos, que nascem de uma ideia central só - a de proteção dos vulnerabilizados a partir dos mesmos fundamentos jurídicos -, a serem sustentados pela construção racional dos seus fundamentos de existência.

\section{CONSTRUÇÃo DOS DIREITOS HUMANOS A PARTIR DA INTERSEÇÃO ENTRE A TEORIA DO DIÁlOgO DAS FONTES E O PENSAMENTO JURÍDICO RACIONAL}

A construção racional do pensamento jurídico é o que permite o desenvolvimento da Teoria do Diálogo das Fontes. Isso porque a própria Teoria do Direito exige a discussão sobre racionalidade jurídica, já que ela, inevitavelmente, será utilizada para solução de situações tidas enquanto jurídicas.

Inicialmente, o termo "razão" tem um duplo significado - um subjetivo e um objetivo. Pelo subjetivo, a razão aparece como um conjunto dos princípios universais que a humanidade 
utiliza no conhecimento, assim como na ação. Para o objetivo (ou ontológico), a razão é a "razão de ser", o que, na ordem das coisas, desenha a conexão indispensável e universal dessas. São duas significações que se unem e se articulam. A razão, então, como pertencente à estrutura da mente humana, liga-se à razão de ser daquilo que é. Ou seja, com o próprio “Ser”. Traz a ideia de construção do próprio problema (LACROIX, 2009).

A razão tem, em Hegel (1997), um de seus fundamentos de existência. Para ele, explicar um fenômeno é dizer a sua razão, não a sua causa. A razão, para ele, é conceitual, abstrata, e refugia-se na mente e nos raciocínios. Assim, é a razão que deve conduzir o pensamento e as ações jurídicas, já que qualquer ação fundada em uma única boa razão é permitida e, perante ela, é possível ficar com uma tranquila certeza moral. O racional é o objetivo visto do lado do subjetivo.

Para Descartes (1979, p. 29), “[...] o poder de bem julgar e distinguir o verdadeiro do falso, que é propriamente o que se denomina o bom senso ou razão, é naturalmente igual em todos os homens". Assim, a mesma razão está presente em todo homem, numa universalidade que deixa ver, na razão, a separação entre a natureza humana e natureza animal.

Então, a razão é a autorreflexão do pensamento, e é movida pela exigência de uma reunificação crítica do saber, com a intenção de recuperação de sua identidade. Ela tem um papel regulador, e é produtora das ideias. É ela que orienta o conhecimento (LACROIX, 2009).

Mas, na atualidade, não há como falar de racionalidade sem falar de dogmática. E falar em dogmática, para Vidal (2013), é falar de império da lei. Para ela, a lei existe para atender à necessidade de segurança e previsibilidade jurídicas, como uma baliza para a liberdade pessoal, e sendo de racionalidade projetiva.

Vidal (2013) também destaca que a previsibilidade do direito lhe dá uma ideia de objetivação. Não a todo custo, mas a partir de sua construção racional, utilizando-se da argumentação jurídica, a partir de determinados valores que fundamentarão direitos iguais. Assim, os direitos se fundamentarão uns nos outros. E, se forem tratados de forma verdadeiramente igual, a proteção dada a um será estendida aos outros.

Por essas ideias, percebe-se que a razão de ser, então, está em operacionalizar e reorganizar a dogmática, utilizando-se da racionalidade jurídica para assegurar direitos e garantias dos vulnerabilizados, sustentando uma igualdade substancial entre eles, direito constitucional indispensável para a composição de uma sociedade livre, justa e solidária, conforme preconiza a Constituição Federal, em seu art. $3^{\circ}$, I. 
Kaufmann (2002) entende que a razão humana só consegue atingir o todo a partir da multiplicidade das partes, que precisa ser construída a partir da confluência entre os diversos discursos, o que requer interação, intersubjetividade, consenso, convergência. A variedade de "pontos de vista" e o pluralismo da doutrina não representam, se forem bem interpretados, um obstáculo. Representam, pelo contrário, uma condição necessária para o completo desenvolvimento e reconhecimento dos direitos.

Tais ideias são afluentes dos princípios constitucionais da isonomia e da dignidade, e vão sustentar a existência do diálogo das fontes, que se funda na proteção de uns direitos partindo de outros. Então, é essa multiplicidade de direitos e de justificativas que vai assegurar o real desenvolvimento do mundo jurídico, pela ideia da racionalidade voltada ao futuro - a verdadeira evolução social.

É por isso que os direitos e princípios constitucionais vão circundar e sustentar a necessidade de conjugação entre os interesses dos diversos ramos do direito, a partir de valores coletivos, que se sobreporão aos individuais. Assim, as justificativas propostas pelo mundo do direito devem servir não à exclusão de direitos ou ramos, mas à construção e proteção de uns e outros.

Cabe destaque ao fato desses direitos fundamentais da pessoa humana terem surgido, inicialmente, com o movimento social dos primeiros cristãos, na Antiguidade do mundo Mediterrâneo, aplicando, para sua construção, as noções de pessoa, ética e liberdade da moral cristã primitiva (PACHÊCO, 2005). Pachêco prescreve:

\begin{abstract}
Alguns elementos dessa "nova" cidadania podem ser retomados, como referimos, de movimentos populares do início de nossa Era. Com esses movimentos constroem-se novas concepções nas relações interpessoais e sociais. Promoveram-se rupturas com as normas e costumes de seu tempo e inovou-se no campo da ética. Essas concepções reaparecem, numa dimensão laica, no que se convencionou denominar movimento humanista, que influencia significativamente o Renascimento e o Iluminismo, curiosamente movimentos anticlericais, demonstrando, historicamente, a dialética e as contradições que o cristianismo encerra, enquanto sistema de ideias (seu aspecto filosófico) e enquanto religião (seu aspecto institucional) (PACHÊCO, 2005, p. 55-56).
\end{abstract}

Esses direitos essenciais eram vistos, até então, de forma individualizada. Contudo, por motivo do crescimento "das sociedades" em dimensão e complexidade, o conceito de direitos humanos passou a sofrer transformações mais radicais. Já que as ações e os relacionamentos assumiram, cada vez mais, o caráter coletivo, em detrimento do individual, as sociedades 
modernas passaram a sentir a necessidade de se afastar da visão individualista dos direitos (CAPPELLETTI, 1988).

Esse individualismo, para Comparato (2010), foi sendo substituído, a partir do século XIX, pelo princípio da solidariedade, que se tornava um dever jurídico:

\begin{abstract}
A solidariedade prende-se à ideia de responsabilidade de todos pelas carências ou necessidades de qualquer indivíduo ou grupo social. É a transposição, no plano da sociedade política, da obligatio in solidum do direito privado romano. O fundamento ético desse princípio encontra-se na ideia de justiça distributiva, entendida como a necessária compensação de bens e vantagens entre as classes sociais, com a socialização dos riscos normais da existência humana.

Com base no princípio da solidariedade, passaram a ser reconhecidos como direitos humanos os chamados direitos sociais, que se realizam pela execução de políticas públicas, destinadas a garantir o amparo e proteção social aos mais fracos e mais pobres; ou seja, aqueles que não dispõe de recursos próprios para viver dignamente (COMPARATO, 2010, p. 77).
\end{abstract}

Essa ideia de solidariedade, que se liga ao princípio da dignidade, traz os direitos humanos para o centro do sistema jurídico, fazendo repensar sobre os motivos de existência e as formas de proteção desses direitos. Para Boaventura de Sousa Santos (1997, p. 11-12),

\begin{abstract}
Os direitos humanos estão no cerne desta tensão: enquanto a primeira geração de direitos humanos (os direitos cívicos e políticos) foi concebida como uma luta da sociedade civil contra o Estado, considerando como o principal violador dos direitos humanos, a segunda e a terceira gerações (direitos econômicos e sociais e direitos culturais, da qualidade de vida etc.) pressupõem que o Estado é o principal integrante dos direitos humanos.
\end{abstract}

A partir disso, algumas concepções abstratas vão passar a circundar os direitos humanos: “[...] i) uma condição etérea (existência imaterial); ii) uma dimensão absoluta (dados de uma vez por todas), e iii) uma variedade universal (no tempo e no espaço)" (ESCRIVÃO FILHO; SOUSA JÚNIOR, 2016, p. 22). Esses direitos dos quais o Estado é garante, então, não podem ser vistos como separados. Eles devem estar relacionados uns aos outros.

Assim, as ideias de maior ou menor salvaguarda dos direitos surgiram a partir da consideração de alguns deles enquanto essenciais à condição humana, o que trouxe uma mudança de paradigma, causando grande impacto (inclusive do Direito Internacional) sobre a ordem constitucional de cada Estado, pois atingiu suas Constituições, que tiveram que se adequar à nova ordem de universalidade de direitos (EMERIQUE, 2006, p. 51-90).

Então, não se permite mais pensar na restrição à visualização dos direitos dos quais o Estado é o garantidor de forma isolada, individualizada. É preciso ultrapassar essas barreiras para 
tratá-los como pertencentes a um todo - o ordenamento jurídico -, merecendo especial e total resguardo, a partir da conjugação entre todos eles, enquanto direitos humanos que são.

$\mathrm{E}$ os direitos dos grupos vulnerabilizados, como as mulheres, se encaixam nessa condição, de forma que se torna indispensável o reconhecimento estatal para a efetiva asseguração deles. Para isso, as atividades a serem desenvolvidas precisam tomar por fundamento um núcleo comum, que envolve os direitos humanos e os faz importantes para o ordenamento jurídico.

Isso se permite a partir do momento em que o Estado constrói suas ações de proteção aos direitos seguindo os parâmetros da racionalidade jurídica, partindo do diálogo entre as diversas fontes que permeiam o mundo do direito, e que impõem um respeito indissolúvel aos direitos humanos como um eixo central.

E o processo de interpretação é essencial para que isso se torne uma realidade, vez que, é a partir dele que são fixados o sentido e o alcance das regras jurídicas, que podem exigir uma maior ou menor extensão do conteúdo jurídico de cada regra.

No caso dos direitos humanos, essa extensão se alonga até que eles sejam absolutamente respeitados, permitindo-se, inclusive, a ultrapassagem dos limites legislativos, costumeiros e jurisprudenciais (entre outros), de modo a se admitir que fontes de diferentes ramos dialoguem entre si para que os direitos sejam efetivamente protegidos.

Antônio Benjamin (2012, p. 5-7) reconhece no diálogo entre as fontes um método de interpretação, integração e aplicação das normas, a partir da superação dos desafios trazidos pela necessidade de coerência e efetividade, impostos pelo pensamento jurídico racional, dada a sistematização do direito e a existência de tantas fontes, ligadas - todas - à Constituição, e também aos seus valores e direitos fundamentais.

Esses valores são os que devem estar no centro do direito. Eles precisam conduzir qualquer interpretação tida como jurídica, assegurando-se o respeito à essência do direito quando da solução das controvérsias jurídicas, visando alcançar sua ratio, sob a coordenação da Constituição Federal, com seus valores e os direitos humanos que os guiam (MARQUES, 2012).

A interpretação jurídica, então, se torna fundamental na consagração de direitos, uma vez que é ela que conduzirá à necessária relação entre eles. Nessa linha, Soriano (1993, p. 245) reconhece que: 
que la interpretación es una actividad residual sólo válida para las normas especialmente oscuras y contradictorias. [...] La interpretación jurídica es, pues, una actividad necesaria y predicable de todas las normas del ordenamiento jurídico, ya sea o no su expresión clara, porque no sólo hay que interpretar su contenido en sí mismo, sino la relación sistemática de las normas $[\ldots]$.

E é a interpretação que vai permitir ao lidador do direito chegar onde pretende. $\mathrm{Na}$ realidade, como ressalta Ferraz Junior (1995), deve haver um princípio dogmático que limite a interpretação ao infinito, pois, se não for assim, o ato interpretativo seguirá por um rumo para o qual não foi feito. Mas, de outro lado, as "[...] múltiplas vias que podem ser escolhidas [...]" asseguram uma liberdade ao intérprete, que deve criar “[...] condições para uma decisão possível” (1995, p. 73).

A falta de respeito aos direitos-centro do ordenamento demonstra as deficiências da interpretação e do raciocínio desenvolvidos, além da ausência de fundamento essencialmente jurídico para a solução da questão. Desse modo, é preciso que, na construção de um raciocínio jurídico, esteja assegurado o respeito aos direitos humanos, e que, para a viabilidade disso, se permita que diferentes ramos do direito dialoguem entre si, o que vai garantir a efetiva aplicação da ideia de direito na construção social.

\section{O DIÁlOGO DAS FONTES COMO CONTRIBUTO PARA A PROTEÇÃo HORIZONTAL DOS DIREITOS DAS MULHERES}

A sustentação do diálogo das fontes não se dá em razão de fundamentos históricos iguais. Na verdade, cada grupo vulnerabilizado, assim como cada "parte" desse grupo, pode ter suas razões históricas de vulnerabilidade. Mas, apesar dessas poderem ser desiguais, é a razão da própria vulnerabilidade que vai sustentar a correlação entre umas fontes e outras.

Para que o diálogo entre as fontes desses vários ramos ocorra e resulte produtivo à salvaguarda dos direitos, torna-se indispensável assegurar o respeito ao núcleo fundamental que protege o bem jurídico, que é o que vai permitir a realização de uma interpretação que adira à lógica racional do sistema jurídico.

Assim, foge-se da limitação ao (apenas) texto da legislação, expandindo-se seu conteúdo para atingir situações não abrangidas por ele, em razão do elo que os liga: a 
vulnerabilidade equitativa entre os indivíduos. A partir daí, aplica-se a fonte que melhor couber à situação, por assegurar o efetivo respeito aos direitos humanos.

E várias razões justificam sua posição de vulnerabilidade ainda hoje. A noção do homem como dominador da natureza e dela mesma, assim como a crença no papel superior da mente racional foram sustentadas pela tradição judaico-cristã, que traz a imagem de um deus masculino, personificação da razão máxima e fonte do poder maior, que governa o mundo a partir do alto e lhe impõe sua lei divina (CAPRA, 2006).

Mas não são só os fundamentos religiosos que sustentam a vulnerabilidade das mulheres ainda hoje. Outros motivos históricos, como os sexuais e de descendência, por exemplo, também podem ser ressaltados como tendo contribuído para a asseguração da supremacia masculina ao longo da história.

Para Engels (1984), o próprio desejo feminino de manter relações sexuais com um homem só figurou como uma, à época, libertação das mulheres (já que substituía as relações obrigatórias com múltiplos parceiros). Ainda, a vontade de tornar a paternidade indiscutível e de concretizar a sucessão dos bens aos legítimos herdeiros também contribuíram para a diminuição das liberdades das mulheres e, por consequência, asseguraram a predominância masculina. À mulher, então, passaram a ficar restritos os direitos relativos ao lar e aos filhos, de modo que qualquer reação feminina contrária aos costumes passava a ser severamente castigada.

Há, na realidade (e ainda hoje), uma verdadeira "construção social dos corpos", que estão “[...] revestidos de significação social - o movimento para o alto sendo, por exemplo, associado ao masculino, como a ereção ou a posição superior no ato sexual” (BOURDIEU, 2005, p. 16).

Apesar da existência de tantas justificações históricas (além das citadas), existe uma característica que vai reger a situação geral das mulheres: a vulnerabilidade. Alguns instrumentos internacionais passaram a reconhecer-lhes direitos em meados do século passado:

De facto, em 1950 foi adotada uma ferramenta específica: a Convenção sobre os Direitos Políticos da Mulher (1952) que reconhece o direito ao sufrágio ativo e passivo para as mulheres em todos os processos eleitorais, assim como o direito a exercer cargos políticos e públicos. A esta, seguiram-se outras convenções internacionais centradas noutros tipos de direitos como a Convenção sobre a Nacionalidade das Mulheres Casadas (1957), a Convenção sobre o Consentimento para Casamento, Idade Mínima para Casamento e Registo dos Casamentos (1962) ou a Convenção sobre o Consentimento para Casamento, Idade Mínima para Casamento e Registo dos Casamentos (1965) (LUGO, 2014, p. 145-170, itálico da autora). 
Mas, contra as práticas de violência contra elas só surgiu, em 1975, a Convenção sobre a Eliminação de todas as Formas de Discriminação contra as Mulheres (CEDAW), derivada da I Conferência Mundial sobre a Mulher, no México. Com o objetivo de igualar formal e materialmente os gêneros e de auxiliar na não discriminação das mulheres, foi o primeiro instrumento internacional criado para a proteção dos direitos dessa, tendo como metas a erradicação da discriminação, preservando seus direitos políticos, civis, econômicos e socioculturais (LUGO, 2014, p. 145-170).

Segundo Piovesan (2004, p. 194), “Em julho de 2001, essa Convenção contava com 168 Estados-partes". Todavia, "[...] a Convenção sobre a Eliminação de todas as formas de Discriminação contra a Mulher enfrenta o paradoxo de ser o instrumento que recebeu o maior número de reservas formuladas pelos Estados, dentre os tratados internacionais de direitos humanos" (PIOVESAN, 2004, p. 195).

Em 1993, na Conferência Mundial sobre Direitos Humanos, deu-se início à elaboração da Declaração sobre Eliminação da Violência contra a Mulher. Mas, somente após dois anos, foi criada a Convenção para Prevenir, Punir e Erradicar a Violência Contra a Mulher, conhecida como "Convenção de Belém do Pará", aprovada pela Organização dos Estados Americanos (OEA) (LUGO, 2014, p. 145-170).

Essa Convenção alargou a Declaração e o Programa de Ação da Conferência Mundial de Direitos Humanos (na cidade de Viena, em 1993), representando a tentativa de sensibilizar os Estados-membros dessa Organização para a violência contra as mulheres (LUGO, 2014, p. 145170).

Todas as formas de violência contra as mulheres passavam a ser combatidas por esses instrumentos: as ocorridas no meio familiar, na unidade doméstica, na comunidade, ou mesmo as cometidas por qualquer outra pessoa. Abrangiam ainda a violência praticada ou aceita pelo Estado ou por quem lhe representa (LUGO, 2014, p. 145-170).

Por intermédio da "Convenção de Belém do Pará", então, buscou-se estabelecer que essa violência constitui séria violação aos direitos humanos, uma ofensa à dignidade das mulheres, que segue na contramão dos ideais de isonomia (LUGO, 2014, p. 145-170).

E isso também é destacado pela Declaração Universal dos Direitos Humanos, que faz menção à garantia da igualdade entre todos os seres humanos em seus artigos $2^{\circ}, 7^{\circ}$ e $16^{\circ}$.

No que tange à Constituição Federal, quando se fala em igualdade entre homens e mulheres, diz-se que ela está consubstanciada em seu art. $5^{\circ}$, caput, bem como em todas os 
dispositivos constitucionais que proíbem discriminação de sexo, como os artigos $5^{\circ}$, inciso I, $3^{\circ}$, inciso IV, e $7^{\circ}$, inciso XXX.

Mas, apesar das inúmeras recomendações de organismos e regramentos internacionais (e também da Constituição Federal) no sentido de serem elaboradas medidas de combate à violência contra as mulheres, a partir da proteção dos seus direitos, essas situações continuam permeando a sociedade.

E o mesmo acontece com outros tantos grupos vulnerabilizados, como negros, indígenas, crianças e adolescentes, idosos, populações tradicionais. E várias das situações de violência a esses grupos também tiveram seu nascedouro no ambiente familiar:

A família pressupôs, por muito tempo, a correção do marido sobre a mulher, o criado, o discípulo, filhos e escravos, e, por mais tempo, a obediência civil da mulher ao marido. Este caráter é reatualizado no modo como, hoje, as agressões domésticas são tratadas segundo eventos únicos, associados às "vias de fato" e lesões levíssimas, de acordo com sua in/significância e i/materialidade (MACHADO, 2014, p. 131-144).

$\mathrm{Na}$ realidade, os direitos desses grupos são diariamente violados, e tais situações são tratadas com "naturalidade", uma vez que as suas posições sociais são pré-fixadas em grau diminuído, como se eles pertencessem inalteravelmente a essa posição. E isso faz com que eles mereçam gozar da mesma proteção, já que passam pela mesma vulnerabilidade.

Então, é porque eles são igualmente vulnerabilizados e desprotegidos que se torna necessária a utilização, para esses grupos, de fundamentos protetivos que se comuniquem, não bastando que cada grupo fundamente individualmente a existência dos seus direitos.

É preciso mais: que uns se fundamentem nos outros, para que haja uma proteção horizontal entre eles. E a horizontalidade dessa proteção se dá pela ausência de hierarquia entre os grupos, já que todos eles têm alicerces e precisam de proteção hierarquicamente iguais, razão pela qual se torna importante a utilização do diálogo entre as fontes para auxiliar nessa proteção.

Para Cláudia Lima Marques (2012), a utilização do diálogo das fontes deve privilegiar a proteção dos direitos do mais vulnerável - no caso deste trabalho, os direitos das mulheres -, partindo de uma releitura desses direitos sob a égide protecionista.

A doutrina, então, se apresenta como responsável pela interseção entre as diversas fontes afetas a cada um dos ramos, de modo que parte dela o desenvolvimento do diálogo das fontes para o reconhecimento dos direitos de uns grupos pelo que fora juridicamente estabelecido 
para outros. E isso é feito, por ela, por meio de um processo de interpretação integracionista do ordenamento jurídico.

Então, é preciso que, através do pensamento jurídico racional, seja feita a conjugação dos diversos grupos vulnerabilizados, privilegiando o empoderamento deles. Esses processos precisam acontecer nos momentos de conflitos, que é quando

[...] se expressam relações de poder, as quais devem ser encaradas não como algo estanque e determinado, mas plástico, flexível, portanto modificável pela ação-reflexãoação humanas, na medida em que os indivíduos compreendam sua inserção histórica passada, presente e futura e sintam-se capazes e motivados para intervir em sua realidade (KLEBA; WENDAUSEN, 2009, p. 742).

A partir do diálogo das fontes, então, assegura-se o empoderamento aos grupos, que segue na contramão da individualização e do enfraquecimento, que só servem para manter os grupos invisibilizados.

A título de legislação brasileira, além da Lei Maria da Penha (Lei no 11.340/2006), que é a "responsável" por fazer a proteção das mulheres, tem-se o Estatuto do Índio (Lei no 6.001/1973), o Estatuto da Criança e do Adolescente (Lei no 8.069/1990), a lei que define crimes resultantes de preconceito de raça ou cor (Lei $n^{\circ}$ 9.459/1997), o Estatuto do Idoso (Lei $n^{\circ}$ 10.741/2003), a que assegura proteção aos povos quilombolas (Decreto $n^{\circ} 4.887 / 2003$ ) e dos povos tradicionais (Decreto $\mathrm{n}^{\circ}$ 6.040/2007), o Estatuto da Pessoa com Deficiência (Lei $\mathrm{n}^{\circ}$ 13.146/2015), entre tantas outras que servem para reconhecimento de direitos aos grupos vulnerabilizados.

Mas cada uma dessas legislações, assim como os direitos que partem delas e dos demais instrumentos internacionais de proteção, são vistas de forma individualizada, o que enfraquece sua existência e mantém não reconhecidos os direitos dos grupos. Com isso, apenas se retroalimenta o sistema de vulnerabilização.

Desse modo, a simples existência das legislações nacionais ou internacionais, ou mesmo de instituições de proteção dos grupos vulnerabilizados, não é suficiente, por si só, para a salvaguarda dos seus interesses. Pensar de outro modo representaria uma inversão à ordem correta:

[...] tal inversão consiste em apresentar o produto como se fosse o próprio fundamento, de tal forma que as normas ou direitos já reconhecidos institucionalmente passem a constituir, em si, os direitos humanos (ESCRIVÃO FILHO; SOUSA JÚNIOR, 2016, p. 25). 
Assim, não são as leis ou as instituições "os próprios direitos humanos". É necessário que eles emerjam delas, a partir dos processos de lutas sociais, assumindo uma forma concreta de existência.

É preciso, então, um efetivo fomento ao respeito aos direitos humanos dos grupos vulnerabilizados (em especial os direitos das mulheres), o que se pode fazer com socialização do diálogo sobre a razão de proteção deles, que é uma só - a vulnerabilidade -, de modo que o reconhecimento do direito de um grupo implica, necessariamente, no reconhecimento dos direitos também dos outros.

\section{CONCLUSÃO}

O trabalho realizado conduziu à ideia de que o diálogo das fontes trouxe uma mudança paradigmática no que tange ao reconhecimento dos direitos dos grupos vulnerabilizados, sob a perspectiva de proteção dos direitos das mulheres.

A partir de uma construção racional desses direitos, permitiu-se comparar os fundamentos de existência dos grupos vulnerabilizados, e perceber que há um eixo comum que recobre e caracteriza todos eles - a vulnerabilidade -, o que exige uma visão coletivizada desses direitos, na medida em que se permite sustentar uns nos outros, em razão dessa característica comum.

Não reconhecer a necessidade de integração entre os direitos dos vários grupos vulnerabilizados só permite que se reitere a situação de vulnerabilidade na qual eles se encontram.

Assim, torna-se necessária uma interpretação de modo a estender os efeitos das fontes existentes e destinadas a um grupo a todos os demais que estejam em igual situação, para que se consiga atingir a real completude e unidade do ordenamento jurídico.

E é só a partir dessas interseções entre as fontes dos vários ramos do direito que se torna possível pensar numa preservação efetiva dos direitos humanos, em especial dos direitos das mulheres, aliadas às ideias de igualdade e dignidade, que são fundamentais ao mundo do direito. 


\section{REFERÊNCIAS}

ADEODATO, João Maurício. Ética \& retórica: para uma teoria da dogmática jurídica. São Paulo: Saraiva, 2012, p. 285-316.

BELTRÃO, Jane Felipe et al. Direitos Humanos dos Grupos Vulneráveis. Manual. Rede Direitos Humanos e Educação Superior, 2014. Disponível em: https://www.upf.edudhesalfamaterials. Acesso em: 17 de maio de 2016, p. 128-201.

BENJAMIN, Antônio Herman. Prefácio. In: MARQUES, Claudia Lima (Coord.). Diálogo das fontes: do conflito à coordenação de normas do direito brasileiro. São Paulo: Revista dos Tribunais, 2012, p. 5-7.

BEVILÁQUA, Clóvis. Teoria Geral do Direito Civil. 2. ed. revista e corrigida. São Paulo: Servanda, 2015.

BOBBIO, Norberto. Teoria do Ordenamento Jurídico (tradução de Maria Celeste C. J. Santos). 10. ed. Brasília: Editora Universidade de Brasília, 1999.

BOURDIEU, Pierre. A dominação masculina (tradução de Maria Helena Kühner). 4. ed. Rio de Janeiro: Bertrand Brasil, 2005.

BRASIL. Constituição (1988). Constituição da República Federativa do Brasil. Brasília: Senado, 2016.

BRASIL. Lei $\mathbf{n}^{\mathbf{0}}$ 11.340, de 7 de agosto de 2006. Cria mecanismos para coibir a violência doméstica e familiar contra a mulher, nos termos do $\S 8^{\circ}$ do art. 226 da Constituição Federal, da Convenção sobre a Eliminação de Todas as Formas de Discriminação contra as Mulheres e da Convenção Interamericana para Prevenir, Punir e Erradicar a Violência contra a Mulher; dispõe sobre a criação dos Juizados de Violência Doméstica e Familiar contra a Mulher; altera o Código de Processo Penal, o Código Penal e a Lei de Execução Penal; e dá outras providências. Brasília: Senado, 2015.

CAPPELLETTI, Mauro. Acesso à Justiça. Porto Alegre: Fabris, 1988.

CAMPOS, Gabriel Junqueira. Diálogo das fontes: um método de resolução das antinomias. Jornal Eletrônico das Faculdades Integradas Vianna Junior. Ano V. Edição I, 2013, p. 7993. 
CAPRA, Fritjof. O ponto de mutação. São Paulo: Ed. Cultrix, 2006.

COMPARATO, Fábio Konder. A afirmação histórica dos direitos humanos. 7. ed. rev. atual. São Paulo: Saraiva, 2010, p. 13-81.

ONU. Declaração Universal dos Direitos Humanos. Disponível em

http://www.dhnet.org.br/direitos/deconu/textos/integra.htm. Acesso em: 18 de fevereiro de 2015.

DESCARTES, René. Discurso do método (Coleção Os Pensadores). São Paulo: Abril Cultural, 1979.

EMERIQUE, Lilian Márcia Balmant. Constitucionalismo: mudanças de paradigma e alguns reflexos sobre os direitos fundamentais. In: GUERRA, Sidney (Coord.). Temas emergentes de direitos humanos (Coleção José do Patrocínio - vol. V). Campos dos Goytacazes: Editora Faculdade de Direito de Campos, 2006, p. 51-90.

ENGLES, Friederich. A Origem da família, da propriedade privada e do Estado. Rio de Janeiro: Civilização Brasileira, 1984.

ESCRIVÃO FILHO, Antonio; SOUSA JUNIOR, José Geraldo de. Para um debate teóricoconceitual e político sobre os direitos humanos. Belo Horizonte: Editora D’Plácido, 2016, p. $13-50$.

FERRAZ JÚNIOR, Tércio Sampaio. A ciência do direito. 2. ed. São Paulo: Atlas, 1995, p. 6886.

HEGEL, Georg Wilhelm Friedrich. Princípios da Filosofia do Direito. São Paulo: Martins Fontes, 1997.

KAUFMANN, Arthur. Introdução à filosofia do direito e à teoria do direito contemporâneas. Lisboa: Fundação Calouste Gulbenkian, 2002, p. 25-46.

KLEBA, Elisabeth; WENDAUSEN, Agueda. Empoderamento: processo de fortalecimento dos sujeitos nos espaços de participação social e democrática. Saúde Soc. v. 18, nº 4, São Paulo, 2009, p. 733-743. 
LACROIX, Alain. A razão: análise da noção, estudo de textos: Platão, Aristóteles, Kant, Heidegger. Petrópolis, RJ: Vozes, 2009, p. 7-19.

LUGO, Yolanda Gómez. Sistema internacional de proteção dos direitos humanos das mulheres. In: BELTRÃO, Jane Felipe et al. Direitos Humanos dos Grupos Vulneráveis. Manual. Rede Direitos Humanos e Educação Superior, 2014. Disponível em: https://www.upf.edudhesalfamaterials. Acesso em: 17 de maio de 2016, p. 145-170.

MACHADO, Lia Zanotta. Gênero e Direitos humanos: revolução de ideias e políticas públicas Contexto geral. In: BELTRÃO, Jane Felipe et al. Direitos Humanos dos Grupos Vulneráveis. Manual. Rede Direitos Humanos e Educação Superior, 2014. Disponível em:

https://www.upf.edudhes-alfamaterials. Acesso em: 17 de maio de 2016, p. 131-144.

MARQUES, Claudia Lima (Coord.). Diálogo das fontes: do conflito à coordenação de normas do direito brasileiro. São Paulo: Revista dos Tribunais, 2012.

PACHÊCO, Marcos Antônio Barbosa. Estado multicultural e direitos humanos: tópica constitucional de direitos étnicos. São Luís: UFMA, 2005.

PAZ, Joseph. Razón práctica y normas (traducción de Juan Ruiz Manero). Madrid: Centro de Estudios Constitucionales, 1991, p. 173-207.

PIOVESAN, Flávia. Direitos Humanos e o Direito Constitucional Internacional. São Paulo: Max Limonad, 2004, p. 194-202.

SANTOS, Boaventura de Sousa. Por uma concepção multicultural de direitos humanos. Revista Crítica de Ciências Sociais, Coimbra, n. 48, p. 11-31, junho, 1997.

SORIANO, Ramón. Compendio de Teoría General del Derecho. 2. ed. corregida y aumentada. Córcega: Editorial Ariel, 1993, p. 121-168; 245-304.

VIDAL, Isabel Lifante. Seguridad jurídica e previsibilidad. DOXA, Cuadernos de Filosofia del Derecho, $n^{\text {o } 36, ~ 2013, ~ p . ~ 85-105 . ~}$ 